\title{
Mediterránea
}

\section{Manual de gestión de la comunicación corporativa [Reseña]}

\section{Corporate communication management manual [Review]}

Fechas | En edición: 11/10/2020 - Publicación final: 01/01/20121

\section{Mg. Sabina Civila}

Universidad de Huelva. España. sabicivila@gmail.com

\section{Manual de gestión de la comunicación corporativa}

Autor: L.M Romero-Rodriguez

Madrid: Tecnos, 2020.

178 páginas

ISBN: 978-84-309-8098-7

\section{Resumen}

Con la situación actual, el público se mueve principalmente por Internet, provocando que se busque la diferenciación a través de las experiencias más que por la venta. El Manual de gestión de la comunicación corporativa es un texto académico en el que se exponen los nuevos retos de las organizaciones en esta área. En este sentido, es de gran importancia el desarrollo de estrategias de identidad de marca para que la percepción de las audiencias sea positiva.

\section{Palabras clave}

Identidad; marca; responsabilidad social; reputación corporativa.

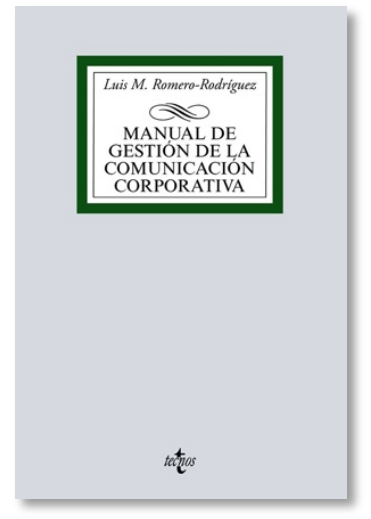

\section{Keywords}

Identity, brand; social responsibility; corporate reputation. 


\section{Introducción}

En el momento histórico actual las tecnologías de la información (TIC) se han convertido en una herramienta esencial para la creación de imagen de marca y el acercamiento de las organizaciones a la sociedad, ya que el público se encuentra principalmente en plataformas online, es por ello que, Luis Miguel Romero Rodríguez profesor e investigador de la Universidad Rey Juan Carlos (Madrid), en la Facultad de Ciencias de la Comunicación, presenta su obra Manual de gestión de la comunicación corporativa donde expone temas como el medioambiente, la igualdad, las prácticas éticas, el cumplimiento de las normas, la participación con el entorno, el uso de materias primas orgánicas y todo lo que implica la Responsabilidad Social Corporativa (RSC). El manual está compuesto de un total de 7 capítulos que conforman 178 páginas donde se explora esta materia desde lo más general a lo más específico, haciendo un recorrido por los nuevos retos a los que deben enfrentarse las organizaciones. En cada uno de los capítulos se desarrolla la teoría a través de ejemplos, simulaciones y ejercicios prácticos, ofreciendo al final preguntas para el debate que ayudan a fomentar el pensamiento crítico, el bate y la discusión de saberes sobre esta temática. Este trabajo busca ser de gran importancia pedagógica tanto para la enseñanza de la asignatura de comunicación corporativa como para las organizaciones y sus Dircom, ofreciendo conceptos de forma teórica y práctica en función de una estructura piramidal. Se comienza con la radiografía de la personalidad de marca, identidad, cultura e imagen corporativa, pasando por los programas y estrategias para realizar una buena comunicación y finalizando en la Responsabilidad Social Corporativa (RSC), la reputación y las crisis organizacionales. Todo ello, adaptado a los nuevos tiempos y a las nuevas generaciones (millennial, generación Y...) que son mucho más exigentes con las empresas y su responsabilidad social.

\section{Resumen}

En el momento social de cambio que se encuentra el mundo, impulsado por la pandemia del virus Covid19 , se esta producción una variación en la forma de trabajar, de comprar, de relacionarse y por supuesto de entender la responsabilidad de las marcas. La presencia del público en Internet ha aumentado, popularizándose el teletrabajo, las compras online, los eventos virtuales, la deslocalización y la descentralización. En este contexto, la conexión con los skateholders es cada vez más complicada y la creación de lazos fuertes y estables se convierte en una ruda tarea. El ecosistema, para tomar decisiones de compra esta sobre saturado, lo que según Luis Miguel Romero-Rodríguez, doctor en Comunicación por las universidades de Huelva, Sevilla, Málaga y Cádiz, está provocando que la comunicación corporativa se posicione como uno de los pilares fundamentales de cualquier organización.

Los puntos principales del manual se ven reflejado en cada uno de sus capítulos de forma clara y precisa. En el primer capítulo, se hace comprender al lector la saturación de productos y servicios homogéneos, lo que lleva a una introducción de la importancia de la gestión estratégica, la personalidad de marca y la identidad corporativa. Se explican sus múltiples conceptos y elementos sin olvidar la correlación que esto tiene con la imagen corporativa, que se alimenta de las percepciones de la audiencia. Es relevante generar engagement con los skateholders, ya que las nuevas plataformas de opinión y valoración que ofrece la web (Trip Advisor, Booking, El Tenedor...) y las redes sociales provocan que la organización pierda el control de la información y sean los propios seguidores los encargados de transmitir una imagen positiva o negativa de la misma, influyendo de manera directa en la reputación de la organización. En el segundo capítulo, se exploran los diferentes valores que una organización debe tener para actuar de forma coherente, lo que afectará la proyección de imagen en la praxis corporativa. El tercer capítulo, sobre gestión y análisis de la identidad corporativa, examina los públicos y evidencia que la identidad de la organización es el reflejo de la filosofía y de la cultura corporativa. Según el autor, las nuevas generaciones inmersas en el mundo digital exigen a las organizaciones coherencia entre lo que se comunica y las acciones que se llevan a cabo, reclamando compromiso social con las prácticas éticas y el cumplimiento de las normas. En el cuarto capítulo se habla del Plan de Comunicación Corporativa (PCC) y se enseña de forma práctica como elaborar un manual de gestión de imagen y comunicación (MAGICO) incluyendo el Plan Estratégico de Imagen Corporativa (PEIC) y el Plan de Comunicación Corporativa (PCC) para realizar una buena proyección de la imagen y alcanzar reputación. Así surge la propuesta de Luis Miguel Romero Rodríguez de realizar mapas de públicos, que tiene como objetivo esclarecer el target, acercarse a ellos y comprender sus atractivos. Cada grupo tiene intereses distintos, por lo que se destaca como importante, diferenciar entre la imagen que se quiere proyectar desde la organización, la que se proyecta por los medios y la real, que es como la comprenden los públicos. En el quinto capítulo, se explora la RSC revisando la jerarquización de los públicos objetivos con el fin de priorizar estrategias y actividades. El éxito de la reputación corporativa depende de la elaboración de un plan de Responsabilidad Social Corporativa, que se estudia y se desarrollan sus etapas de elaboración a lo largo del presente capítulo. Así, en el sexto apartado el autor considera que la reputación debe ser explicada como un proceso de 
conversión simbólico expectativas-valor que se transforma en valor emocional asociado a la marca a través del comportamiento pasado, presente y futuro de la empresa. El incremento de la reputación no solo depende de los medios convencionales, sino también de las nuevas plataformas donde los contenidos generados por influencers pueden tener un gran alcance. En el último capítulo, se revisan los riesgos, ya que de acuerdo con Luis Miguel Romero Rodríguez un pequeño fallo puede verse incrementado a través de las redes sociales, aumentando el enfrentamiento de los públicos objetivos y poniendo en riesgos la estabilidad de la empresa, pudiendo afectar de forma negativa a su reputación. Ante las crisis comunicacionales es importante contar con una herramienta que ayude a la resolución rápida y efectiva, evitando que el conflicto aumente y favoreciendo su disminución.

En resumen, este libro es interesante para profesores de la presente asignatura, investigadores de la temática y DIRCOM, ya que evidencia que la actitud que deben tomar las empresas con respecto a la comunicación corporativa está vinculada a la dinámica relacional de los públicos, resaltando que es importante para los gabinetes de comunicación y Dircom contar con una serie de recomendaciones actualizadas y adaptadas al contexto actual, que podrán ser encontradas en Manual de gestión de la comunicación corporativa.

\section{Valoración}

El presente manual contiene material innovador, constatando la necesidad de cambio de la responsabilidad social corporativa en las organizaciones y de adaptación a los nuevos tiempos y a las generaciones modernas. Se remarca y se considera un aspecto fuerte del manual, los ejemplos gráficos y prácticos para comprender de forma clara y sencilla los diferentes conceptos expuestos a lo largo del documento, así como, el apartado de asuntos a debatir que se expone al final de cada capítulo. Se valora el libro como innovador y actual destacando como única limitación el uso de escasas referencias, aunque la calidad de la contribución se concentra en el avance científico que el texto supone, cumpliendo así su objetivo de convertirse en un referente del área temática. Utiliza un lenguaje académico pero cercano que permite el entendimiento del contenido a cualquier lector, convirtiéndose en un ejemplo de divulgación científica. 